\title{
Erythematous Nodule With Central Erosions on the Calf
}

Paul J. Shim, BS; David Terrano, MD; Henna Pearl, MD; Burrell Wolk, MD; Neil Fernandes, MD

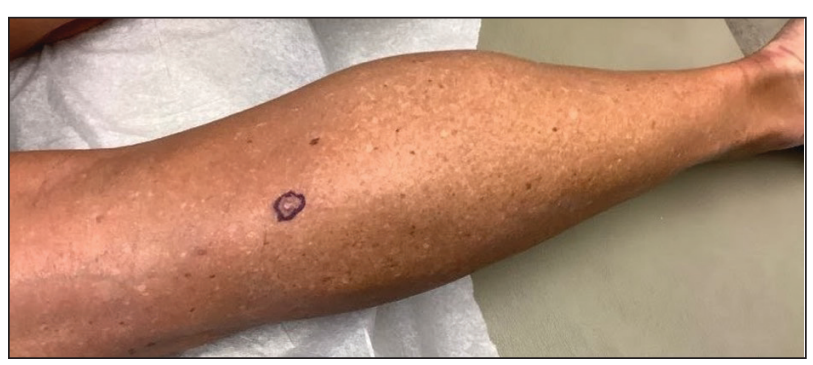

A 62-year-old woman presented with an irregular, erythematous, 4-mm nodule with central erosions on the left proximal calf of 2 months' duration. The patient had a history of actinic keratoses and dysplastic nevi. She had no other notable medical history. She was not taking any medications and reported no history of trauma to the area. A shave biopsy of the lesion (encircled by black ink) was performed.

\section{WHAT'S YOUR DIAGNOSIS?}
a. dermatofibroma
b. keratoacanthoma
c. osteoma cutis
d. pilomatricoma
e. prurigo nodularis

Mr. Shim and Dr. Fernandes are from the Department of Dermatology, University of Arizona College of Medicine, Phoenix. Dr. Terrano is from Aurora Diagnostics, Scottsdale, Arizona. Drs. Pearl and Wolk are from and Dr. Fernandes also is from Skin and Cancer Center of Arizona, Chandler. The authors report no conflict of interest.

Correspondence: Neil Fernandes, MD, 725 S Dobson Rd, Ste 200, Chandler, AZ 85224 (nff3@columbia.edu). doi:10.12788/cutis.0399 


\section{THE DIAGNOSIS: Osteoma Cutis}

○ steoma cutis is the heterotopic development of cutaneous ossifications in the dermis or subcutaneous fat and presents as plaquelike, stony, hard nodules. It can manifest as either a primary or secondary condition based on the presence or absence of a prior skin insult at the lesion site. Primary osteoma cutis occurs in $15 \%$ of patients and arises either de novo or in association with any of several inflammatory, neoplastic, and metabolic diseases that provide a favorable environment for abnormal mesenchymal stem cell commitment to osteoid, ${ }^{1}$ including Albright hereditary osteodystrophy, myositis ossificans progressiva, and progressive osseous heteroplasia, which are all associated with mutations in the heterotrimeric G-protein alpha subunit encoding gene, GNAS. ${ }^{1,2}$ It is suggested that an insufficiency of $G_{s} \alpha$ leads to uncontrolled negative regulation of nonosseous connective tissue differentiation, forming osteoid. ${ }^{3}$ Additionally, diseases involving gain-of-function mutations in the activin $\mathrm{A}$ receptor type 1 encoding gene, ACVR1, such as fibrodysplasia ossificans progressiva, have been associated with osteoma cutis. ${ }^{4}$ These mutations lead to decreased receptor affinity to molecular safeguards of bone morphogenetic protein signaling, ultimately contributing to progressive ectopic bone formation. ${ }^{5}$ Secondary osteoma cutis occurs in $85 \%$ of patients and develops at the site of prior skin damage due to inflammation, neoplasm, or trauma. 6 It is believed that tissue damage and degeneration lead to mesenchymal stem cell proliferation and skeletogenicinducing factor recruitment forming cartilaginous tissue, later replaced by bone through endochondral ossification. ${ }^{7}$

Although osteoma cutis previously was believed to be rare, more recent radiologic studies suggest otherwise, detecting cutaneous osteomas in up to $42.1 \%$ of patients. ${ }^{8}$ Consequently, it is likely that osteoma cutis is underdiagnosed due to its subclinical nature. Our patient, however, presented with a solitary osteoma cutis with perforation of the epidermis, a rare phenomenon. ${ }^{9-12}$

A shave biopsy in our patient revealed moderate to focally marked, irregular epidermal hyperplasia with a large focus of moderate, compact, parakeratotic crust overlying the epidermis in the center of the specimen. The papillary dermis in the center of the specimen revealed large foci of dark pink to purple bone fragments surrounded by moderate lymphocytic infiltrate with few foci perforating through the overlying epidermis (Figure, A). These findings were characteristic of osteoma cutis with perforation through the overlying epidermis.

The diagnosis of osteoma cutis at the age of 62 years suggested that the lesion was not primary in association with previously described diseases. Furthermore, the lack of phenotypic features of these diseases including obesity, developmental disability, and high parathyroid hormone
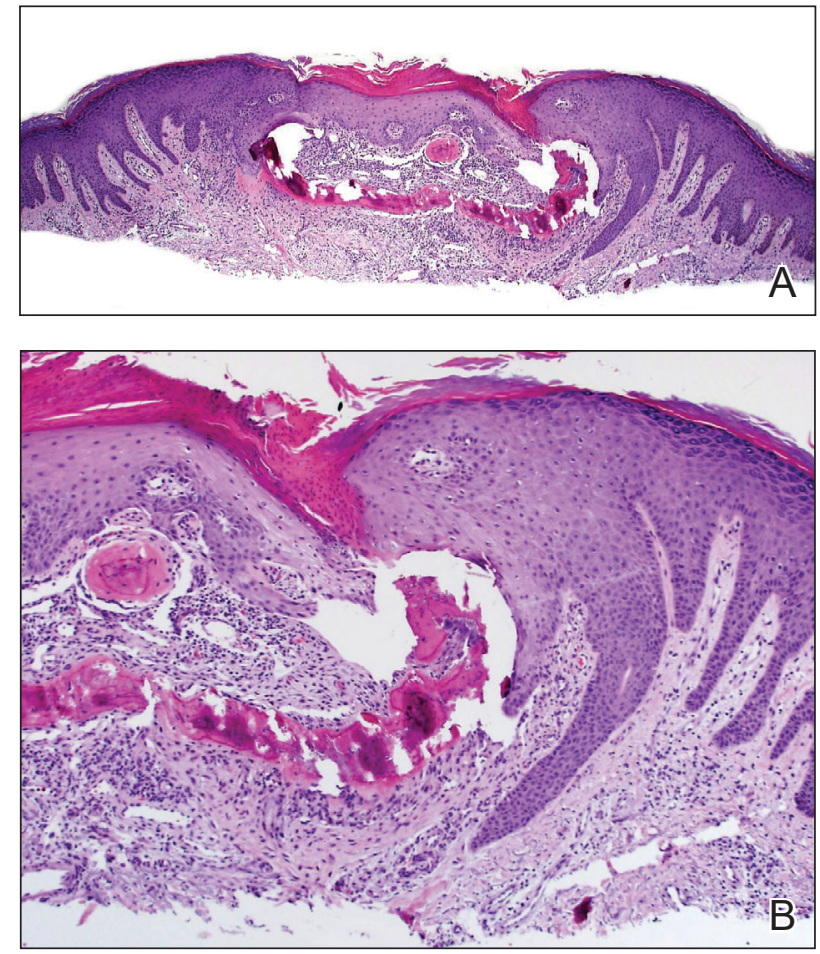

A and B, Osteoma cutis on the proximal left calf. Large foci of dark pink to purple bone fragments surrounded by a moderate lymphocytic infiltrate with few foci perforating through the overlying epidermis $(H \& E$, original magnifications $\times 4$ and $\times 10)$.

levels essentially excluded this possibility. The presence of the lesion on the lower extremities initially may have suggested osteoma cutis secondary to chronic venous insufficiency ${ }^{13}$; however, the absence of visible varicose veins or obvious signs of stasis disease made this unlikely. No further cutaneous disorders at or around the lesion site clinically and histologically suggested that our patient's lesion was primary and of idiopathic nature. Dermatofibroma can present similarly in appearance but would characteristically dimple centrally when pinched. Keratoacanthoma presents with central ulceration and keratin plugging. Pilomatricoma more commonly presents on the head and neck and less frequently as a firm nodule. Lastly, prurigo nodularis more commonly presents as a symmetrically diffuse rash compared to an isolated nodule.

Osteoma cutis is a cutaneous ossification that may be primary or secondary in nature and less rare than originally thought. Workup for potentially associated inflammatory, neoplastic, and metabolic diseases should be considered in patients with this condition. Perforating osteoma cutis is a rare variant that presents as solitary or multiple nodules with central erosion and crust. The 
mechanism of transepidermal elimination leading to skin perforation is hypothesized to involve epidermal hyperproliferation leading to upward movement. ${ }^{14}$ Shave biopsy establishes a definitive histopathologic diagnosis and often is curative. Given that lesions of osteoma cutis themselves are benign, removal may not be necessary.

\section{REFERENCES}

1. Falsey RR, Ackerman L. Eruptive, hard cutaneous nodules in a 61-yearold woman. osteoma cutis in a patient with Albright hereditary osteodystrophy (AHO). JAMA Dermatol. 2013;149:975-976.

2. Martin J, Tucker M, Browning JC. Infantile osteoma cutis as a presentation of a GNAS mutation. Pediatr Dermatol. 2012;29:483-484.

3. Shore EM, Ahn J, de Beur SJ, et al. Paternally inherited inactivating mutations of the GNAS1 gene in progressive osseous heteroplasia. N Engl J Med. 2002;346:99-106.

4. Kaplan FS, Le Merrer M, Glaser DL, et al. Fibrodysplasia ossificans progressiva. Best Pract Res Clin Rheumatol. 2008;22:191-205.

5. Song GA, Kim HJ, Woo KM, et al. Molecular consequences of the ACVR1(R206H) mutation of fibrodysplasia ossificans progressiva. J Biol Chem. 2010;285:22542-22553.
6. Roth SI, Stowell RE, Helwig EB, et al. Cutaneous ossification. report of 120 cases and review of the literature. Arch Pathol. 1963;76:44-54.

7. Shimono K, Uchibe K, Kuboki T, et al. The pathophysiology of heterotopic ossification: current treatment considerations in dentistry. Japanese Dental Science Review. 2014;50:1-8.

8. Kim D, Franco GA, Shigehara H, et al. Benign miliary osteoma cutis of the face: a common incidental CT finding. AJNR Am J Neuroradiol. 2017;38:789-794.

9. Basu P, Erickson $\mathrm{CP}$, Calame A, et al. Osteoma cutis: an adverse event following tattoo placement. Cureus. 2019;11:E4323.

10. Cohen PR. Perforating osteoma cutis: case report and literature review of patients with a solitary perforating osteoma cutis lesion. Dermatol Online J. 2018;24:13030/qt6kt5n92w.

11. Hong SH, Kang HY. A case of perforating osteoma cutis. Ann Dermatol. 2003;15:153-155

12. Kim BK, Ahn SK. Acquired perforating osteoma cutis. Ann Dermatol. 2015;27:452-453.

13. Lippmann HI, Goldin RR. Subcutaneous ossification of the legs in chronic venous insufficiency. Radiology. 1960;74:279-288.

14. Haro R, Revelles JM, Angulo J, et al. Plaque-like osteoma cutis with transepidermal elimination. J Cutan Pathol. 2009;36:591-593. 